\title{
Psychosocial Support for Caregiver
}

National Cancer Institute

\section{Source}

National Cancer Institute. Psychosocial Support for Caregiver. NCI Thesaurus. Code C116698.

Any act that provides mental and emotional succor for a caregiver. 